\title{
SHORT BEDS FOR CHROMATOGRAPHIC MEASUREMENT OF ADSORPTION EQUILIBRIUM CONSTANTS
}

\author{
Dong Il LEe, Mohamed A. FAHIM, Seilchiro KAGUEI and Noriaki WAKAO \\ Faculty of Engineering, Yokohama National University, Yokohama 240
}

The technique of adsorption chromatography has, in recent years, often been applied to the determination of mass transfer parameters such as adsorption equilibrium constant in packed beds.

In practice, chromatographic measurements are made employing adsorption beds of suitable length. The input and response concentrations of the adsorbate imposed on an inert carrier gas are normally monitored using a pair of tungsten filaments placed just above and below the adsorption bed. During measurement, the filaments (electrical resistance in the range of 20-30 $\Omega$ ) with an operating current of $100-150 \mathrm{~mA}$ generate heat. The heat output is small, but may cause considerable temperature rise in the bed in the vicinity of the filaments, particularly at low flow rates. This is demonstrated in Fig. 1, which shows axial temperatures measured at the center of a bed of Molecular Sieves 5A with downward flow of helium.

When the test bed is long enough, the temperature rise effect at the bed-end has little influence on the parameter estimation based on isothermal condition. If the test bed is short, the effect is significant and the bed cannot be assumed to be isothermal. Even in this case, however, uniform temperature may be attained by installing an inert bed between the tungsten filament and the test bed. The inert bed absorbs the heat generated in the filament, thus minimizing the heat effect on the test bed. The analysis becomes somewhat complex, but determination of adsorption equilibrium constant from a short bed is made feasible.

The purpose of this work is to examine the effect of a short adsorption bed on parameter estimation. Adsorption equilibrium constants determined from chromatographic measurements with test beds of various bed lengths are compared and discussed.

Figure 2 shows the packed bed system employed in the measurements. The adsorption bed (Section 3) packed with spherical particles of Davison Molecular Sieves $5 \mathrm{~A}$ (particle size $D_{p}=2 \mathrm{~mm}$; bed void

Received October 3,1981. Correspondence concerning this article should be addressed to N. Wakao, Dept. of Chem. Eng., Yokohama National Univ., Yokohama 240. D. I. Lee is at College of Engineering, Chonnam National Univ., Gwangju, Korea, and M. A. Fahim is at Dept. of Chem. Eng., Univ. of Kuwait, Kuwait. fraction $\varepsilon_{b}=0.38$ ) was located between two inert beds (Sections 2 and 4 ) of glass beads ( $D_{p}=2 \mathrm{~mm}: \varepsilon_{b}^{\prime}=0.38$ ). Nitrogen, as an adsorbing tracer, was imposed on a carrier stream of helium flowing through the $3-\mathrm{cm}$ column at room temperature, $27^{\circ} \mathrm{C}$. The adsorption chromatographic measurements were made with six columns of varied lengths as shown below:

$\begin{array}{ccccl}\text { Column } & \begin{array}{c}L_{D} \\ {[\mathrm{~cm}]}\end{array} & \begin{array}{c}L^{\prime} \\ {[\mathrm{cm}]}\end{array} & \begin{array}{c}L \\ {[\mathrm{~cm}]}\end{array} & \begin{array}{c}L^{\prime \prime} \\ {[\mathrm{cm}]}\end{array} \\ 1 & 0.4 & 5.5 & 1.0 & 3.6 \\ 2 & 0.4 & 4.5 & 2.0 & 3.6 \\ 3 & 0.4 & 4.5 & 3.0 & 2.6 \\ 4 & 0.4 & 3.5 & 4.0 & 2.6 \\ 5 & 0.4 & 0 & 15.4 & 0 \\ 6 & 0.4 & 0 & 20.2 & 0\end{array}$

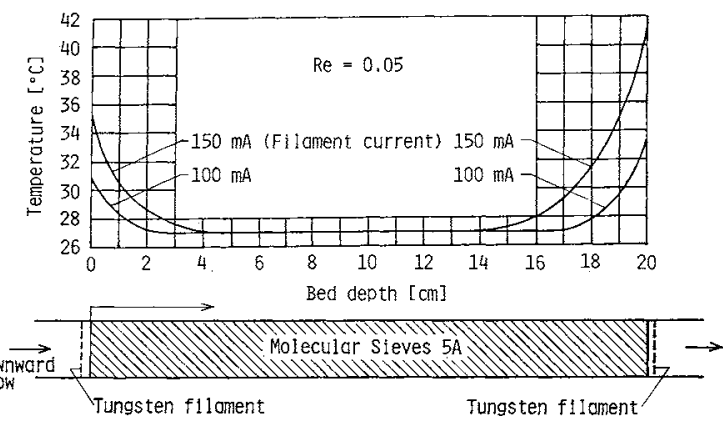

Fig. 1 Bed temperature profiles measured in a $20 \mathrm{~cm}$-long bed of Molecular Sieves $5 \mathrm{~A}$ with helium gas flow at $R e=0.05$

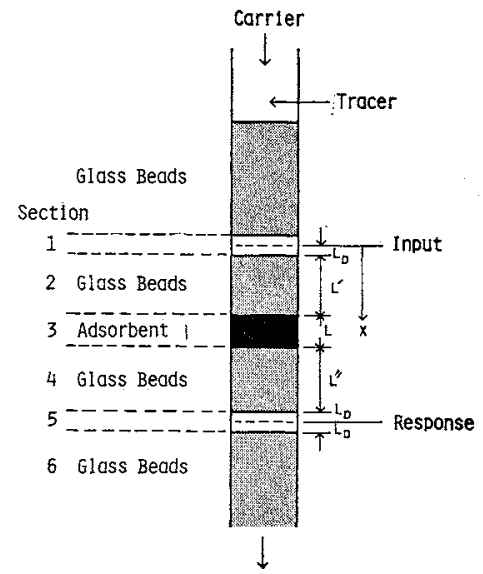

Fig. 2 A column used for adsorption measurements

JOURNAL OF CHEMICAL ENGINEERING OF JAPAN 
The adsorbent, Molecular Sieves 5A, was found to have a density of $1210 \mathrm{~kg} \cdot \mathrm{m}^{-8}$. The intraparticle pore volume fraction was determined to be 0.30 for pore sizes larger than $40 \AA$ using a mercury porosimeter, and the total void fraction was found to be 0.51 by the method of helium displacement. Therefore, the adsorbate, nitrogen gas, which is $3.64 \AA$ in molecular diameter (Lennard-Jones kinetic diameter), is obviously accessible to all the pores of Molecular Sieves $5 \mathrm{~A}$ employed in the study.

The chromatographic measurements were made in the range of Reynolds number less than 0.5 , and the

$$
\begin{gathered}
C_{D}=C^{\prime} \text { and } D_{D} \frac{\partial C_{D}}{\partial x}=\varepsilon_{b}^{\prime} D_{a x}^{\prime} \frac{\partial C^{\prime}}{\partial x}, \\
\text { at } \begin{array}{r}
x=L_{D} ; x=L_{D}+L^{\prime}+L+L^{\prime \prime} ; \\
x=3 L_{D}+L^{\prime}+L+L^{\prime \prime}
\end{array} \\
C^{\prime}=C \text { and } \varepsilon_{b}^{\prime} D_{a x}^{\prime} \frac{\partial C^{\prime}}{\partial x}=\varepsilon_{b} D_{a x} \frac{\partial C}{\partial x}, \\
\text { at } x=L_{D}+L^{\prime} ; x=L_{D}+L^{\prime}+L \\
C^{\prime}=0, \quad \text { at } x=\infty
\end{gathered}
$$

The transfer function relating the input signal, $C^{I}(t)$ at $x=0$, to the response signal, $C^{I I}(t)$ at $x=$ $2 L_{D}+L^{\prime}+L+L^{\prime \prime}$, is

$$
\begin{aligned}
& {\left[\begin{array}{ll}
1 & 0
\end{array}\right] \boldsymbol{M}\left(\lambda_{D}, \xi_{D}, \frac{D_{D}}{L_{D}}\right)\left[\begin{array}{c}
1 \\
\varepsilon_{b}^{\prime} D_{a x}^{\prime} \lambda^{\prime} / L^{\prime}
\end{array}\right] \exp \left[\lambda+2 \lambda_{D}+\lambda^{\prime}+\lambda^{\prime \prime}\right]}
\end{aligned}
$$

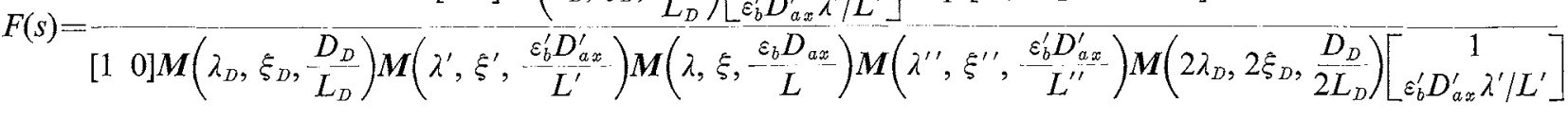

temperature rise in the bed due to the adsorption was less than $0.2^{\circ} \mathrm{C}$. The adsorption bed was then assumed to be under isothermal condition during the measurements.

Material balances of the adsorbate in a column provided with inert beds, in general, give (refer to Fig. 2):

Empty columns-Sections $I$ and 5 (concentration $C_{D}$; gas dispersion coefficient $D_{D}$; gas velocity $u$ ),

$$
\frac{\partial C_{D}}{\partial t}=D_{D} \frac{\partial^{2} C_{D}}{\partial x^{2}}-u \frac{\partial C_{D}}{\partial x}
$$

Inert beds-Sections 2, 4 and 6 (concentration $C^{\prime}$; gas dispersion coefficient $D_{a x}^{\prime}$; interstitial gas velocity $U^{\prime}$ ),

$$
\frac{\partial C^{\prime}}{\partial t}=D_{a x}^{\prime} \frac{\partial^{2} C^{\prime}}{\partial x^{2}}-U^{\prime} \frac{\partial C^{\prime}}{\partial x}
$$

Adsorption bed-Section 3 (concentration in bulk gas $C$; concentration in particle $c$; gas dispersion coefficient $D_{a x}$; interstitial gas velocity $U$; for other symbols see Nomenclature),

$$
\begin{aligned}
& \frac{\partial C}{\partial t}=D_{a x} \frac{\partial^{2} C}{\partial x^{2}}-U \frac{\partial C}{\partial x}-\frac{a}{\varepsilon_{b}} D_{e}\left(\frac{\partial c}{\partial r}\right)_{R} \\
& \varepsilon_{p}-\frac{\partial c}{\partial t}=D_{e} \frac{1}{r^{2}}\left(r^{2} \frac{\partial c}{\partial r}\right)-\rho_{p} \frac{\partial c_{a d}}{\partial t} \\
& D_{e}\left(-\frac{\partial c}{\partial r}\right)_{R}=k_{f}\left(C-(c)_{R}\right)
\end{aligned}
$$

When the tracer concentration in intraparticle pore volume is small, the adsorption rate is assumed to be of first order:

$$
\frac{\partial c_{a d}}{\partial t}=k_{a}\left(c-\frac{c_{a d}}{K_{A}}\right)
$$

The initial and boundary conditions are

$$
\begin{array}{ll}
C_{D}=C^{\prime}=C=c=c_{a d d}=0, & \text { at } t=0 \\
C_{D}=C^{I}(t), & \text { at } x=0
\end{array}
$$

where

$$
\begin{aligned}
& \boldsymbol{M}(\alpha, \beta, \gamma)=\frac{1}{\beta-\alpha} \\
& {\left[\begin{array}{cl}
\beta-\alpha \exp [\alpha-\beta] & -(1-\exp [\alpha-\beta]) / \gamma
\end{array}\right.} \\
& \alpha \beta \gamma(1-\exp [\alpha-\beta])-(\alpha-\beta \exp [\alpha-\beta]) \\
& \lambda_{D}=\left(L_{D} u /\left(2 D_{D}\right)\right)\left(1-\sqrt{1}+4 D_{D} s / u^{2}\right) \\
& \xi_{D}=\left(L_{D} u /\left(2 D_{D}\right)\right)\left(1+\sqrt{1}+4 D_{D} s / u^{2}\right) \\
& \lambda^{\prime}=\left(L^{\prime} U^{\prime} /\left(2 D_{a x}^{\prime}\right)\right)\left(1-\sqrt{1+4 D_{a x}^{\prime} s / U^{\prime 2}}\right) \\
& \xi^{\prime}=\left(L^{\prime} U^{\prime} /\left(2 D_{a x}^{\prime}\right)\right)\left(1+\sqrt{1+4 D_{a x}^{\prime} s / U^{\prime 2}}\right) \\
& \lambda^{\prime \prime}=\left(L^{\prime \prime} U^{\prime} /\left(2 D_{a x}^{\prime}\right)\right)\left(1-\sqrt{1}+4 \bar{D}_{a x}^{\prime} s / \bar{U}^{\prime 2}\right) \\
& \xi^{\prime \prime}=\left(L^{\prime \prime} U^{\prime} /\left(2 D_{a w}^{\prime}\right)\right)\left(1+\sqrt{1}+4 D_{a x}^{\prime} s / U^{\prime 2}\right) \\
& \lambda=\left(L U /\left(2 D_{a x}\right)\right)\left(1-\sqrt{\left.1+\overline{\left(4 D_{a x} /\right.} U^{2}\right)(s+q)}\right) \\
& \xi=\left(L U /\left(2 D_{a x}\right)\right)\left(1+\sqrt{ } 1+\left(4 D_{a x} / U^{2}\right)(s+q)\right) \\
& q=\left(a D_{e} /\left(\varepsilon_{b} R\right)\right) /\left(\left(D_{e} /\left(R k_{f}\right)\right)+1 /\left(\phi_{a} \operatorname{coth} \phi_{a}-1\right)\right) \\
& \left.\phi_{a}=R \sqrt{\left(s / D_{e}\right)\left(\varepsilon_{p}+\rho_{p}\right.} \overline{k_{a} K_{A} /\left(K_{A} s+k_{a}\right)}\right)
\end{aligned}
$$

At low temperature, physical adsorption rate constant is usually very large ${ }^{1,4)}$ so that it may be assumed that $k_{a}=\infty^{6}$. In other words, it is shown from Eq. (6) that the adsorbate concentration in the pore volume is in equilibrium with the amount adsorbed:

$$
c_{a d}=K_{A} c
$$

Therefore, Eq. (7k) reduces to

$$
\phi_{a}=R \sqrt{\left(s / \overline{\left.D_{e}\right)}\left(\varepsilon_{p}+\rho_{p} K_{A}\right)\right.}
$$

Note that when the column has no inert beds, $L^{\prime}=L^{\prime \prime}=0$ in Eqs. (7) and (7d) $-(7 \mathrm{~g})$.

At low flow rates, the axial fluid dispersion coefficients in inert beds are related to the molecular diffusion coefficient, $D_{v}$, as ${ }^{2 !}$

$$
D_{a x}^{\prime}=0.65 D_{v}
$$

whereas in the empty column sections the dispersion coefficient is identical with the molecular diffusion coefficient. 


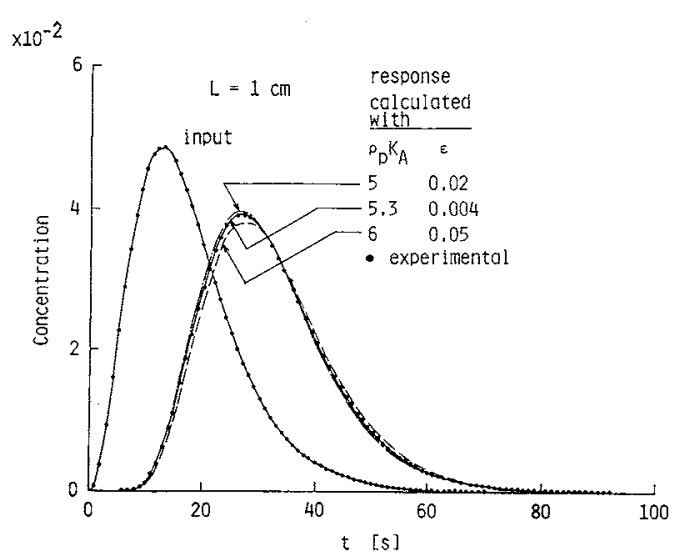

(a) Column 1, $R e=0.1$

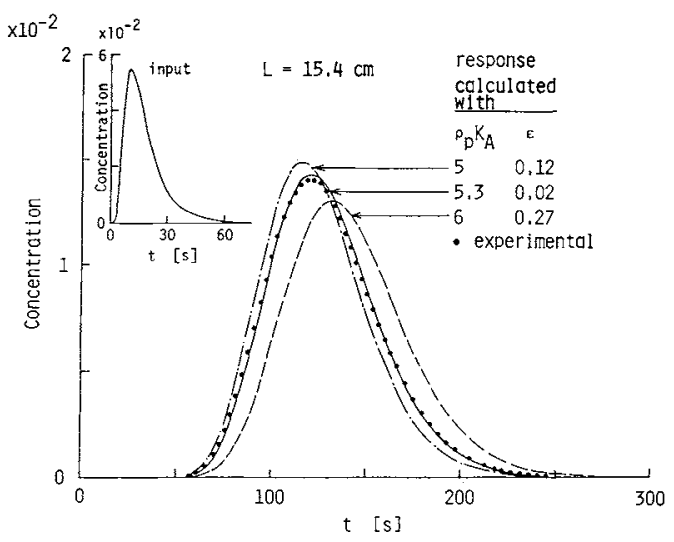

(b) Column 5, $R e=0.1$

Fig. 3 Effect of $\rho_{p} K_{A}$ on computed response signals

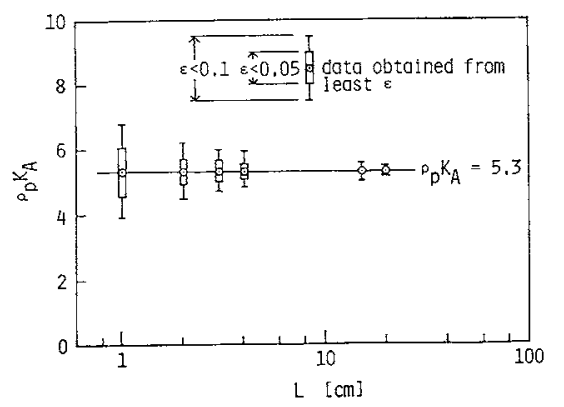

Fig. 4 Adsorption equilibrium constants measured with various adsorption bed lengths

$$
D_{D}=D_{v}
$$

The intraparticle effective diffusivity and axial gas dispersion coefficient of nitrogen for the nitrogenhelium system in a bed of Molecular Sieves $5 \mathrm{~A}$ at $20^{\circ} \mathrm{C}$ have been found ${ }^{3)}$ to be $D_{e}=(0.7-0.8) \times 10^{-6}$ $\mathrm{m}^{2} \cdot \mathrm{s}^{-1}$ and $\varepsilon_{b} D_{a x} / D_{v} \simeq 0.30$. The increase in effective diffusivity with increase in temperature from 20 to $27^{\circ} \mathrm{C}$ is so small $(1 \%$ increase under Knudsen diffusion; $4 \%$ increase under bulk diffusion condition) that the effective diffusivity of nitrogen at $27^{\circ} \mathrm{C}$ is still assumed to be $0.75 \times 10^{-6} \mathrm{~m}^{2} \cdot \mathrm{s}^{-1}$ for Molecular
Sieves $5 \mathrm{~A}$. Note that the molecular diffusivity, $D_{v}$, in the nitrogen-helium system at $27^{\circ} \mathrm{C}$ is $0.74 \times 10^{-4}$ $\mathrm{m}^{2} \cdot \mathrm{s}^{-1}$.

The particle-to-gas mass transfer coefficient may be estimated by a correlation proposed by Wakao and Funazkri ${ }^{5}$ :

$$
S h=2+1.1 S c^{1 / 3} R e^{0.6}
$$

With these estimated parameters and various assumed values of the adsorption equilibrium constant, $K_{A}$, the response signals are predicted, $C_{\mathrm{calc}}^{I I}(t)$, based on the measured input signal by the method of Kaguei $e^{2} a l^{2)}$ The computed signals are then compared with the measured response signal, $C_{\mathrm{exp}}^{I I}(t)$, in the time domain, and the correct value of $K_{A}$ is determined when the root-mean-square-error, $\varepsilon$, defined by Eq. (13), is minimum.

$$
\varepsilon=\left\{\int_{0}^{\infty}\left(C_{\mathrm{exp}}^{I I}-C_{\mathrm{c} \mathrm{a} 1 \mathrm{c}}^{I I}\right)^{2} d t / \int_{0}^{\infty}\left(C_{\mathrm{exp}}^{I I}\right)^{2} d t\right\}^{1 / 2}
$$

As illustrations, the measured and computed response signals are compared in Fig. 3(a) for Column 1 and in Fig. 3(b) for Column 5, both at $R e=0.1$. From Figs. 3(a) and (b) the same adsorption equilibrium constant is obtained: $\rho_{p} K_{A}=5.3$. It is also found that for a long bed (Fig. 3(b)), a slight change in $\rho_{p} K_{A}$ value has a greater effect on the shape of computed response signal than that of a short bed (Fig. 3(a).) This is due to the fact that, for a short adsorption bed, the analysis is made on the entire system consisting of the adsorption bed, dead volume, and inert beds. The inclusion of inert beds then dilutes the sensitivity in estimation of adsorption parameter. This is more clearly seen in Fig. 4. The ranges indicating 5 and $10 \%$ root-mean-square-errors between the measured and predicted response signals widen (the confidence of the obtained $\rho_{p} K_{d}$ value is somewhat reduced) with decreasing bed length, but it should be noted that the same $\rho_{p} K_{A}$ value is obtained from the measurements irrespective of adsorption bed length, which varies from 1 to $20.2 \mathrm{~cm}$. An inert bed a few centimeters long is found to be effective in overcoming the filament-heat effect and eventually obtaining the constant adsorption equilibrium constant.

Note that when the adsorption bed was short and no inert beds were provided in the column, agreement between predicted and measured response signals was always so poor that $\rho_{p} K_{A}$ value could not be determined. This results from the fact that the bed was no longer isothermal and the adsorption equilibrium constant was not constant throughout the bed.

The adsorption equilibrium constant may also be estimated from measurements of breakthrough curve or response to a step input in a long column. However, in general, parameters are more accurately 
estimated from one-shot measurement than from step response. For one-shot measurement a short adsorption bed is usually preferable. It is interesting that a solid-gas adsorption bed as short as five particle layers may successfully be used in estimating the adsorption equilibrium constant provided that inert beds are installed between test bed and concentration detecting filament. A short adsorption bed can be effectively employed, particularly when the system has a large adsorption equilibrium constant and a long time is required to obtain response signal in a conventional long bed.

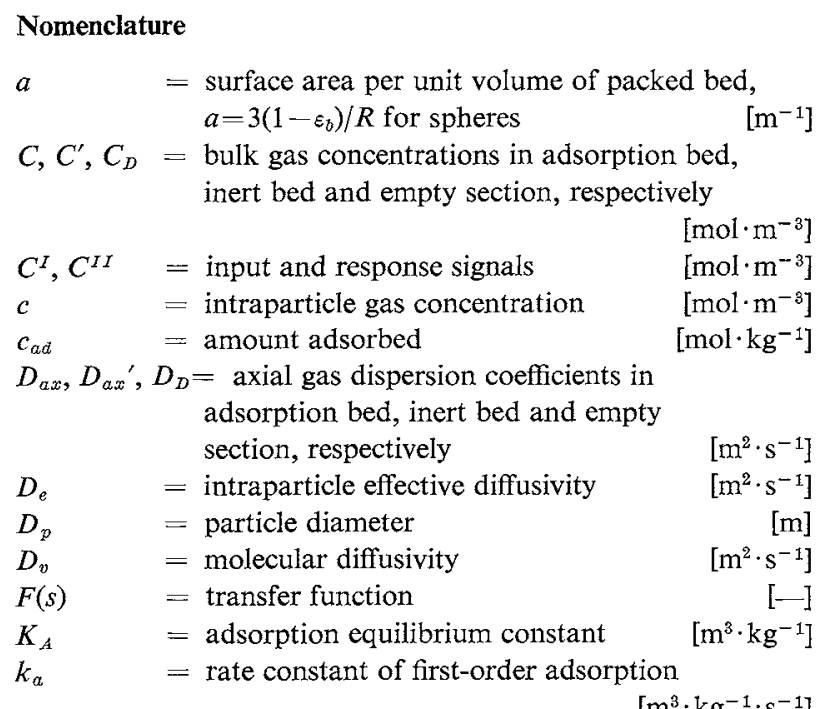

$$
\begin{aligned}
& k_{f} \quad=\text { particle-to-gas mass transfer coefficient } \\
& \begin{array}{l}
L \quad=\text { adsorption bed length } \\
L^{\prime}, L^{\prime \prime}, L_{D}=\text { lengths, refer to Fig. } 2
\end{array} \\
& R \quad=\text { particle radius } \\
& =D_{p} U \varepsilon_{b} \rho_{F} / \mu \text {, Reynolds number } \quad \text { [-] } \\
& \text { Sc } \quad=\mu /\left(\rho_{F} D_{v}\right) \text {, Schmidt number } \quad[-] \\
& \text { Sh } \quad=k_{f} D_{p} / D_{v} \text {, Sherwood number [-] } \\
& U, U^{\prime} \quad=\text { interstitial gas velosities in adsorption } \\
& \text { bed and inert bed, respectively }\left[\mathrm{m} \cdot \mathrm{s}^{-1}\right] \\
& u \quad=\text { gas velocity in empty column } \quad\left[\mathrm{m} \cdot \mathrm{s}^{-1}\right] \\
& \varepsilon \quad=\text { root-mean-square-error, defined by Eq. (13) } \\
& \varepsilon_{b}, \varepsilon_{b}^{\prime}=\text { void fractions in adsorption bed and } \\
& \text { inert bed, respectively } \\
& \varepsilon_{p} \quad=\text { intraparticle void fraction } \\
& =\text { gas viscosity } \\
& =\text { gas density } \\
& =\text { particle density }
\end{aligned}
$$

\section{Literature Cited}

1) Gangwal, S. K., R. R. Hudgins, A. W. Bryson and P. L. Silveston: Can. J. Chem. Eng., 49, 113 (1971).

2) Kaguei, S., K. Matsumoto and N. Wakao: Chem. Eng. Sci., 35, 1809 (1980)

3) Lee, D. I., S. Kaguei and N. Wakao: J. Chem. Eng. Japan, 14, 161 (1981).

4) Schneider, P. and J. M. Smith: AIChE J., 14, 762 (1968).

5) Wakao, N. and T. Funazkri: Chem. Eng. Sci., 33, 1375 (1978).

6) Wakao, N., S. Kaguei and J. M. Smith: Ind. Eng. Chem., Fundam., 19, 363 (1980).

\title{
THE REACTION ORDER OF SOLID CONCENTRATION FOR VOLUME REACTION MODEL
}

\author{
Noboru SAKAI, TADASHI CHIDA AND TEIRIKI TADAKI \\ Department of Mining and Mineral Engineering, Tohoku University, Sendai 980
}

\section{A fluid-solid reaction such as}

$$
\mathrm{A} \text { (fluid) }+\mathrm{S} \text { (solid) }=\text { Products }
$$

has often been analyzed kinetically by the volume reaction model ${ }^{1,3-5}$. In this model, the disappearance rate of component $\mathrm{A}$ per unit volume of bulk solid $\left(-r_{A}\right)$, is assumed to be a function of the fluid and solid concentrations,

$$
\left(-r_{A}\right)=k f\left(C_{A}, C_{S}\right)
$$

Received September 11, 1981. Correspondence concerning this article should be addressed to N. Sakai. T. Tadaki is at Dept. of Chem. Eng
The function $f\left(C_{A}, C_{S}\right)$, however, could not be represented theoretically. Thus the rate has been described approximately by the following form:

$$
\left(-r_{A}\right)=k C_{A} C_{S}^{m}
$$

Chida and Tadaki $^{2}$ reported recently that the solid concentration dependence of the rate can be expressed in the form of Eq. (3), on the basis of a structural model in which a solid pellet is composed of a large number of fine spherical particles. However, the case where $m$ is less than $2 / 3$ could not be explained 